\title{
Comparing non-safety with safety device sharps injury incidence data from two different occupational surveillance systems
}

\author{
A.H. Mitchell ${ }^{a, *}$, G.B. Parker ${ }^{a}$, H. Kanamori ${ }^{b}$, W.A. Rutala ${ }^{\text {b }}$, D.J. Weber ${ }^{b}$ \\ a International Safety Center, Apopka, Florida, USA \\ ${ }^{\mathrm{b}}$ Division of Infectious Diseases, University of North Carolina, Chapel Hill, North Carolina, USA
}

A R T I C L E I N F O

Article history:

Received 5 January 2017

Accepted 21 February 2017

Available online 27 February

2017

Keywords:

Needlesticks

Sharps injuries

Safety-engineered devices

Blood and body fluid exposures

Bloodborne pathogens

Healthcare personnel safety

\author{
$S U M M A R Y$
}

The United States Occupational Safety and Health Administration (OSHA) Bloodborne Pathogens Standard as amended by the Needlestick Safety and Prevention Act requiring the use of safety-engineered medical devices to prevent needlesticks and sharps injuries has been in place since 2001. Injury changes over time include differences between those from non-safety compared with safety-engineered medical devices. This research compares two US occupational incident surveillance systems to determine whether these data can be generalized to other facilities and other countries either with legislation in place or considering developing national policies for the prevention of sharps injuries among healthcare personnel.

\section{Introduction}

It has been 15 years since the incorporation of the new requirements of the Needlestick Safety and Prevention Act (NSPA) into the United States Occupational Safety and Health Administration (OSHA) Bloodborne Pathogens Standard (BPS), to include the requirement to use 'sharps with engineered sharps injury protection' (SESIPS) or medical devices with safety features that prevent workers from sustaining a

\footnotetext{
* Corresponding author. Address: International Safety Center, 741 Muirfield Circle, Apopka, FL 32712, USA. Tel.: +1 7138160013.

E-mail address: amber.mitchell@internationalsafetycenter.org (A.H. Mitchell).
}

contaminated sharp injury or needlestick. ${ }^{1}$ Whereas legislation and subsequent national regulations have been the driving force of adoption in the USA, contaminated sharps injuries are a threat around the world and other countries are using safetyengineered devices to reduce life-threatening occupational exposures to bloodborne pathogens. ${ }^{2-7}$

Whereas there has been a robust body of literature reporting decreases in overall sharps injuries since 2001, there have only been a few published reports comparing injuries from devices with and without safety features. Additionally, whereas employers are required to record injuries in a sharps injury log, under-reporting injuries continues to be a problem area and it is uncertain whether facilities are using their data to analyse their blood and body fluid exposures (BBFEs) and 
sharp object injuries (SOls) to identify any impact or change over time in the source of the injury [i.e. safety-engineered devices (SEDs) vs non-SEDs].

To determine whether incident trends over time are similar across different occupational surveillance systems from different US geographies, this brief report compares healthcare personnel (HCP) exposure incidence data for injuries associated with SEDs and non-SEDs. We have analysed data from two US occupational surveillance databases; University of North Carolina (UNC) Hospital Occupational Health Service Records and International Safety Center Exposure Prevention Information Network (EPINet ${ }^{\circledR}$ ).

Kanamori et al. analysed 4300 BBFEs for a period of 15 years to identify the impact of SEDs on the incidence of sharps injuries at UNC Hospitals. ${ }^{8}$ They demonstrated an overall reduction in SOls due to the impact of SEDs, but they also found that a considerable proportion of injuries are associated with these devices, supporting previous findings. ${ }^{8-10}$

EPINet has been reporting annual aggregate data from its volunteer network of hospitals located around the country since 1992. EPINet BBFE data include needlesticks and sharp object injuries as well as BBFEs (mucocutaneous) and have been used as benchmark data for hospitals around the world for decades. These data have been used to determine the impact of US policies, such as the NSPA and OSHA's subsequent updates to its BPS.

This analysis is designed to corroborate results from UNC compared to EPINet and to identify whether the two databases can be used to provide a generalized illustration of what others may see in their facilities - if in effect they can serve as benchmarks.

\section{Methods}

Our BBFE and sharps injuries included data from US EPINet network hospitals. Since the NSPA was promulgated in 2000 , it serves as the first study period year. Across the study period (2000-2014), the number of contributing hospitals from different states changed (ranging from 58 to 25), therefore BBFE rates are captured using a ratio of number of exposure incidents reported to average daily census (ADC). Annual incidence rates of sharp object injuries (SOIs) were calculated as injuries per $A D C$. We compared incidence data to create incidence rate differences (IRDs) based on generalized linear models over the entire study period and between injuries associated with SEDs versus non-SEDs from each surveillance system for all devices and then for injury from each device type (e.g. injection, infusion, blood collection) for the 15-year time period from 2000 to 2014. Statistical analysis was performed using JMP ${ }^{\circledR} 11$ (SAS Institute Inc., Cary, NC, USA), and $P<0.05$ was considered statistically significant.

\section{Results}

For the EPINet network surveillance data, a total of 21,562 BBFE including 16,698 SOls (77.4\%) were reported. Overall IRD was significantly reduced for all BBFEs and SOls from 2000 to $2014(\mathrm{IRD}=7.5, P=0.043)$, but levelled off and was less changed in 2011 (IRD $=9.0, P=0.046$ during 2000-2011 vs $\mathrm{IRD}=-4.0, P=0.26$ during 2011-2014) (Figure 1). There was a reduction in all SOls from non-SEDs across the entire study period (IRD $=10.4, P=0.008)$, but an increase in SOI from SEDs $(\mathrm{IRD}=-2.9, P=0.045)$

Injuries associated with SEDs accounted for an average of $35.3 \%$ of all BBFE across all years with increases in the last three report years of $36.7 \%$ in 2012, 41.6\% in 2013, and $42.3 \%$ in 2014 .

In the EPINet dataset, BBFE was most frequently due to injecting through skin, drawing a venous blood sample, and suturing. This did change year to year with injection as high as $32.3 \%$ (2014), venous blood collecting as high as $16 \%$ (2000), and suturing as high as $25.6 \%$ (2012) (Figure 2). When comparing all

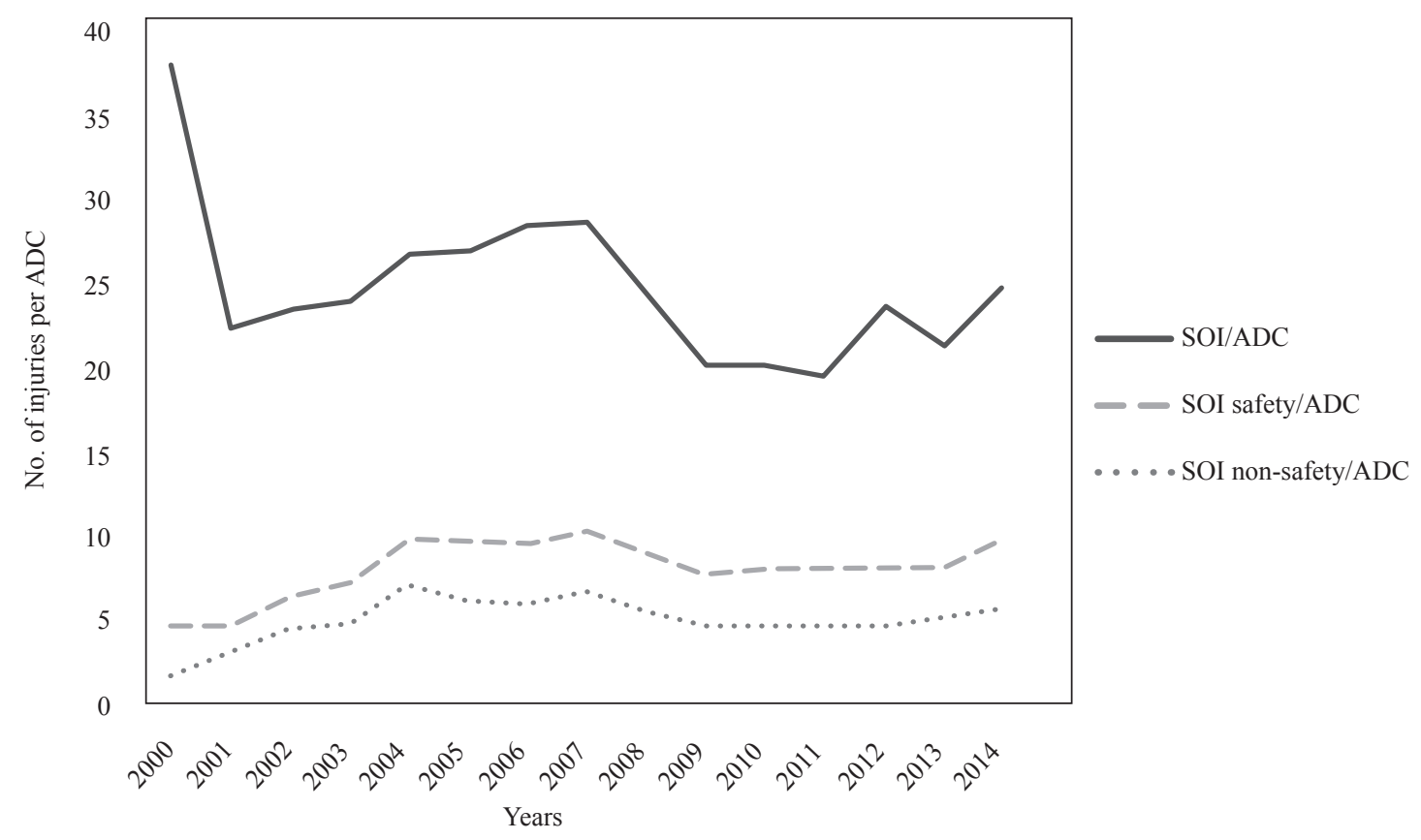

Figure 1. EPINet total sharp object injuries (SOIs) per average daily census (ADC) compared with safety-engineered devices and nonsafety (conventional) devices, 2000-2014. 


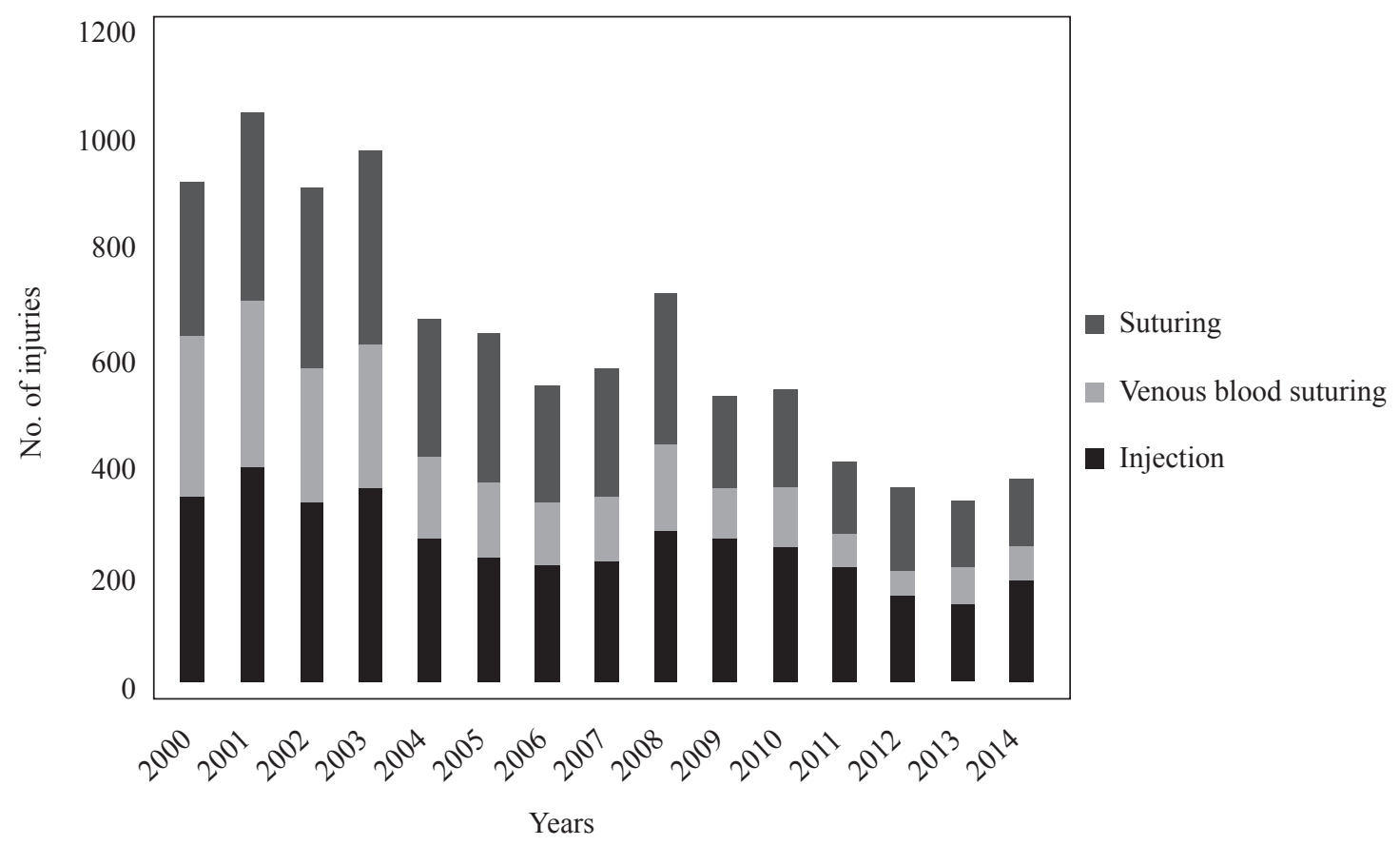

Figure 2. EPINet top three sharp object injuries by procedure, 2000-2014.

SOls with safety mechanisms (i.e. SEDs), EPINet demonstrates that an average of $69.5 \%$ of safety features were not activated during the 2000-2014 reporting period.

\section{Discussion}

Safety-engineered devices worked well to decrease the incidence of SOls from the 2001 NSPA. However, our surveillance system demonstrated an increasing number of injuries with SEDs over time. Whereas the passage of the NSPA and subsequent improvement of requirements under the OSHA BPS did a superb job in reducing sharps injuries because of the implementation of SEDs, the safety function in a majority of currently available SEDs is not passive. They still require the user to activate a safety mechanism or feature (whether sliding sheath, hinged sheath, retracting needle/blade, or blunting needle).

Due to the fact that injuries are increasing from SEDs, as also illustrated in recent data from the Massachusetts Sharps Injury Surveillance System (1198 in 2011; 1290 in 2012; 1341 in 2013; 1326 in 2014), this highlights the need for healthcare facilities to improve not only the training and education associated with the use and activation of SEDs, but also to adhere to requirements to include non-managerial frontline employees in the evaluation and selection of SEDs..$^{1,2,11-15}$ This ensures that SEDs are purchased and available, and that they are selected because they are the best and safest application for the procedures being performed by the HCP performing them. Failure to perceive the risk at hand and subsequent complacency about risk continues to be an issue among HCP who believe BBFEs are 'just a part of the job'. With increasing rates of national and international hepatitis $B$, hepatitis $C$, and emerging infectious disease such as Ebola and Zika, these are risks that HCP cannot afford to take. ${ }^{16}$

In summary, although the overall decline in sharps injuries is a magnificent public health success, we must continue to be diligent about making sure that steady decline is still occurring until occupational risk associated with bloodborne pathogens is as low as possible. This includes renewed focus not only on purchase and availability of SEDs, but also on evaluation, selection and use of the safety mechanisms inherent to their design, as well as education and training on how to use them.

\section{Conflict of interest statement}

None declared.

\section{Funding sources}

None.

\section{References}

1. Occupational Safety and Health Administration. Bloodborne Pathogens Standard, 29 CFR 1910.1030. Available at: https:// www.osha.gov/pls/oshaweb/owadisp.show_document?p_ table $=$ standards\&p_id $=10051$ [last accessed February 2017].

2. Whitby M, McLaws ML, Slater K. Needlestick injures in a major teaching hospital: the worthwhile effect of hospital-wide replacement of conventional hollow-bore needles. Am J Infect Control 2008;36:180-186.

3. Dulon M, Lisiak B, Wendeler D, Nienhaus A. Causes of needlestick injuries in three healthcare settings: analysis of accident notifications registered six months after the implementation of EU Directive 2010/32/EU in Germany. J Hosp Infect 2017;95:306-311.

4. Lamontagne F, Abiteboul D, Lolom I, et al. Role of safetyengineered devices in preventing needlestick injuries in 32 French hospitals. Infect Control Hosp Epidemiol 2007;28:18-23.

5. Fukuda H, Yamanaka Y. Reducing needlestick injuries through safety-engineered devices: results of a Japanese multicenter study. J Hosp Infect 2016;92:147-153.

6. Ballout RA, Diab B, Hard AC, et al. Use of safety-engineered devices by healthcare workers for intravenous and/or phlebotomy procedures in healthcare settings: a systematic review and metaanalysis. BMC Health Serv Res 2016;16:458. 
7. Harb AC, Tarabay R, Diab B, et al. Safety engineered injection devices for intramuscular, subcutaneous and intradermal injections in healthcare delivery settings: a systematic review and meta-analysis. BMC Nurs 2015;14:71.

8. Kanamori H, Weber DJ, DiBiase LM, et al. Impact of safetyengineered devices on the incidence of occupational blood and body fluid exposures among healthcare personnel in an academic facility, 2000-2014. Infect Control Hosp Epidemiol 2016;37:497-504.

9. Tosini W, Ciotti C, Goyer F, et al. Needlestick injury rates according to different types of safety-engineered devices: results of a French multicenter study. Infect Control Hosp Epidemiol 2010;31:402-407.

10. Black L. Chinks in the armor: percutaneous injuries from hollow bore safety-engineered sharps devices. Am J Infect Control 2013;41:427-432.

11. Parker GB, Mitchell A. International Safety Center Exposure Prevention Information Network (EPINet ${ }^{\circledR}$ ) needlestick and sharp object injury and blood and body fluid exposure summary data. Available at: http://internationalsafetycenter.org/exposurereports/ [last accessed August 2016].

12. Massachusetts Department of Public Health. Sharps injuries among hospital workers in Massachusetts, 2011. Massachusetts Sharps Injury Surveillance System. Available at: http://www.mass.gov/ eohhs/docs/dph/occupational-health/injuries/injuries-hospital2011.pdf [last accessed September 2016].

13. Massachusetts Department of Public Health. Sharps injuries among hospital workers in Massachusetts, 2012. Massachusetts Sharps Injury Surveillance System. Available at: http://www.mass.gov/ eohhs/docs/dph/occupational-health/injuries/injuries-hospital2012.pdf [last accessed September 2016].

14. Massachusetts Department of Public Health. Sharps injuries among hospital workers in Massachusetts, 2013. Massachusetts Sharps Injury Surveillance System. Available at: http://www.mass.gov/ eohhs/docs/dph/occupational-health/injuries/injuries-hospital2013.pdf [last accessed September 2016].

15. Massachusetts Department of Public Health. Sharps injuries among hospital workers in Massachusetts, 2014. Massachusetts Sharps Injury Surveillance System. Available at: http://www.mass.gov/ eohhs/docs/dph/occupational-health/injuries/injuries-hospital2014.pdf [last accessed September 2016].

16. American Public Health Association. Preventing occupational transmission of globally emerging infectious disease threats. Available at: https://www.apha.org/policies-and-advocacy/ public-health-policy-statements/policy-database/2015/12/08/ 15/22/preventing-occupational-transmission-of-globallyemerging-infectious-disease-threats [last accessed September 2016]. 